\title{
An uncommon variant of cyanotic congenital heart disease in a young adult female: a rare case of right pulmonary artery to left atrial fistula (PALAF)
}

Ram Sundar Twayana 1*, Sanjaya Humagain ${ }^{1}$, Rajendra Koju ${ }^{1}$, Kriti Subas Joshi², Robin Man Karmarcharya ${ }^{3}$, Sajana $\mathrm{KC}^{4}$ and Navaraj Poudel ${ }^{5}$

\begin{abstract}
Background: Cyanotic congenital heart disease is not a rare entity, but fistula between the right pulmonary artery and the left atrium is an uncommon vascular anomaly. Although it is a real challenge to diagnose the case, detailed clinical evaluation and selective investigations are keys for diagnosis, and surgical intervention is still considered the best treatment option.

Case presentation: A 19 years old girl from the remote village of Nepal presented with the history of exercise intolerance associated with cyanosis and clubbing of the extremities. We diagnosed her as a case of right pulmonary artery to left atrial fistula, a rare variant of pulmonary arteriovenous malformation. She underwent successful surgical correction of the anomaly under cardiopulmonary bypass surgery.

Conclusion: Direct communication between the right pulmonary artery and the left atrium is a rare cyanotic congenital heart disease, which is diagnosed late and often associated with the atrial septal defect. The best treatment available is surgical correction.
\end{abstract}

Keywords: Congenital, Left atrium, Pulmonary artery

\section{Background}

Cyanotic congenital heart disease is not a rare entity but fistula between the right pulmonary artery and left atrium is an uncommon vascular anomaly. A direct shunt between the right pulmonary artery and the left atrium in the presence of intact atrial septum is a rare entity and diagnosis is yet another challenge. In the presenting case, there is an additional angiolipoma in the right posterior chest wall, which we considered as an incidental finding.

\section{Case presentation}

A 19 years old girl from the remote village of Nepal with body mass index (BMI) of 19.5 presented to Kathmandu

\footnotetext{
*Correspondence: dr.ramsundar@gmail.com

'Department of Cardiology, Dhulikhel Hospital, Kathmandu University Hospital, Dhulikhel, Nepal

Full list of author information is available at the end of the article
}

University Hospital, Dhulikhel Hospital complaining of exercise intolerance for several months and bluish discoloration of extremities and lips. She also noticed bilateral bulbous enlargements of the distal end of the fingers and toes. However, there were no significant clinical events during birth, post-natal and childhood periods.

Clinical examinations revealed central and peripheral cyanosis with grade III clubbing of all extremities (Fig. 1) and plethoric lower conjunctiva. However, other systemic examinations showed no abnormal findings.

Investigations showed oxygen saturation at $60 \%$ at room air, which was not corrected by oxygen support. The arterial blood gas analysis report showed the partial pressure of oxygen $\left(\mathrm{PaO}_{2}\right)$ at $44 \mathrm{mmHg}$, venous haemoglobin and haematocrit were $18.6 \mathrm{gm} \%$ and $62.2 \%$, respectively. Transthoracic echocardiography depicted mosaic flow (Fig. 2) from the right pulmonary artery to 

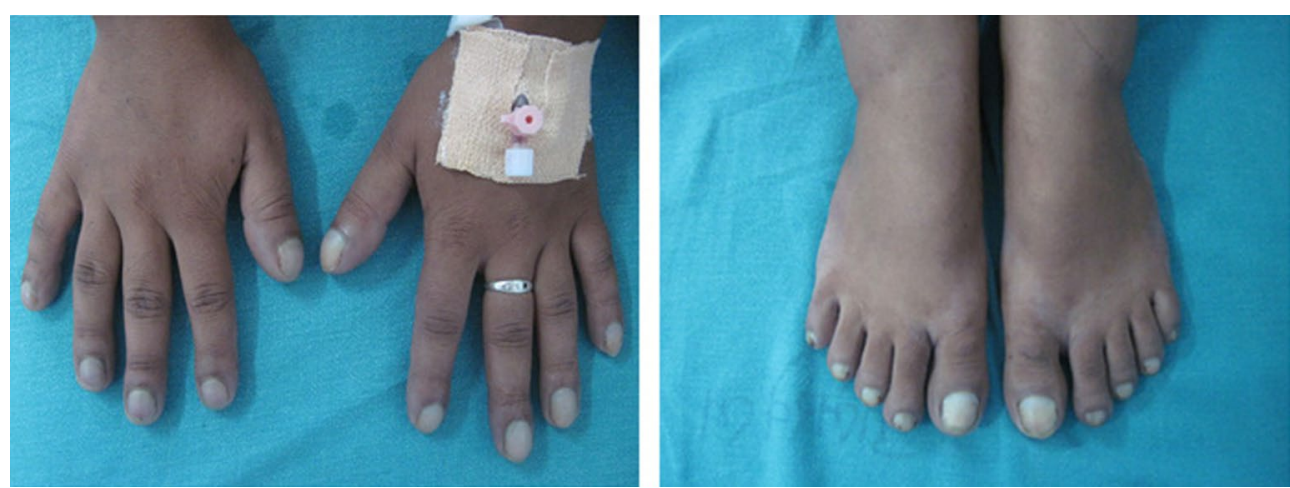

Fig. 1 Showing bilateral grade III clubbing with cyanosis of the extremities

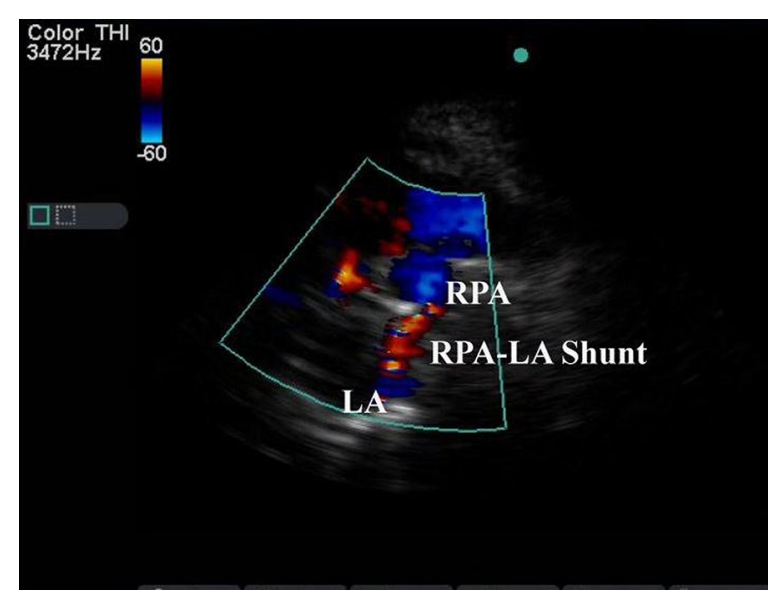

Fig. 2 Transthoracic echocardiography showing shunt. RPA right pulmonary artery, LA left atrium the left atrium (RPA-LA), and grade I pulmonary regurgitation. Chest radiograph and pulmonary function test were normal. Computed tomography $(\mathrm{CT})$ of the chest showed enlarged left atrium and the direct communication from the posterior part of the right pulmonary artery into the left atrium, approximately $25 \mathrm{~mm}$ in size (Fig. 3). There was an additional angiolipoma $(77-55 \mathrm{~mm}$ ) on the right posterior chest wall between the scapula and the chest wall, which we consider an incidental finding (Fig. 4). We performed pulmonary arteriogram, which demonstrated the flow of the contrast from the abnormal branch of the right pulmonary artery to the left atrium (Fig. 5). The $\mathrm{PaO}_{2}$ in the pulmonary trunk and the right pulmonary artery, close to the shunt were 32 and $34 \mathrm{mmHg}$, respectively.

After confirming the diagnosis of the right pulmonary artery to the left atrial fistula, she underwent open

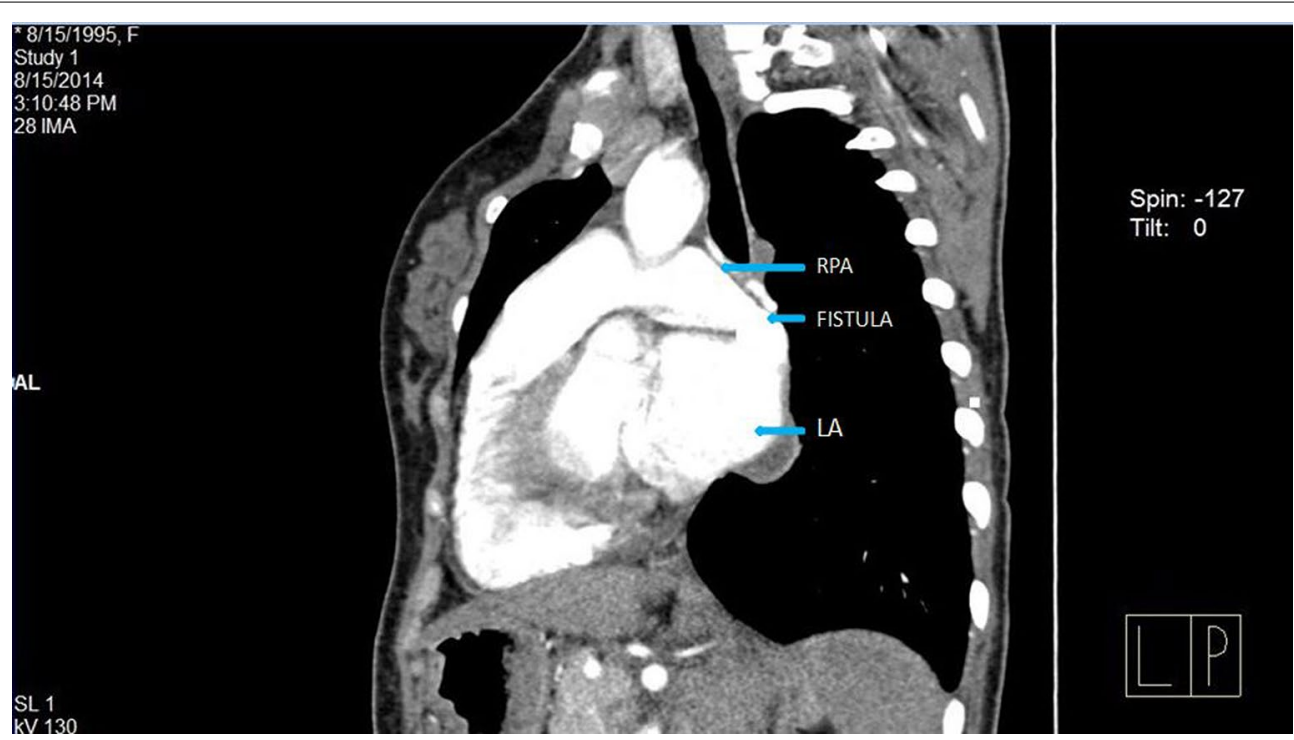

Fig. 3 Contrast enhanced CT chest showing shunt between right pulmonary to left atrium (oblique view) 


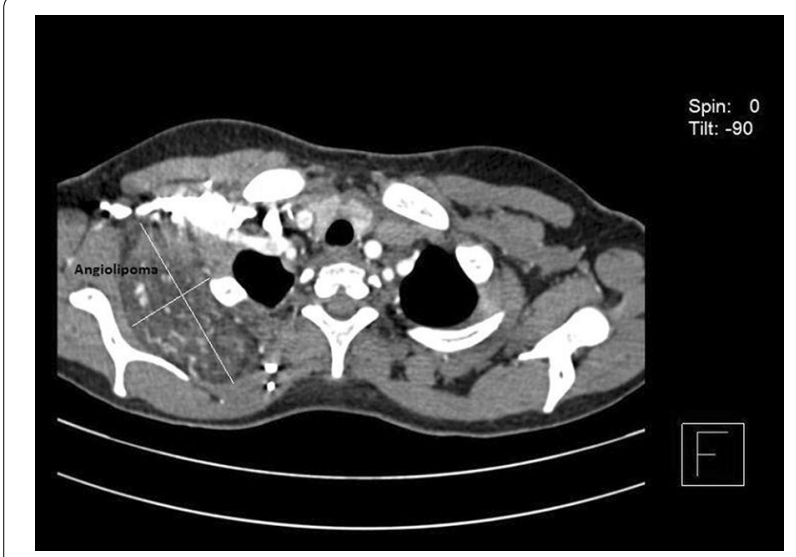

Fig. 4 Angiolipoma between scapula and chest wall (right side)

heart surgery in National Heart Centre. Intra-operative finding showed a direct connection between the right pulmonary artery to the left atrium approximately 1.5$1.3 \mathrm{~cm}$ in size, which was closed using polytetrafluoroethylene patch. Immediately after closer of the shunt, her condition improved with adequate oxygen saturation at $95 \%$ at room air. Her post-operative course was uneventful and discharged. She is now on regular follow up.

\section{Discussion}

One of the rare causes of cyanotic congenital heart disease is a direct communication between RPA-LA, which was first described by Friedlich et al. [1]. This acts as a right to left shunt resulting in cyanosis, dyspnoea on exertion and polycythemia. In addition, the shunt bypasses the capillaries beds and permits emboli or bacteria to enter directly into the systemic circulation causing a stroke or cerebral abscess [2]. In most reported cases, the anomaly arises from the posterior part of the right pulmonary artery connecting the left atrium, between the right and the left pulmonary veins, which is similar in this case. Other commonly associated cardiac anomaly is atrial septal defect thus, causing a chance of missed diagnosis [3]. However, anomalies of the right lung such as an absence of middle or lower lobe, right lung sequestration, and diverticulum of the right main bronchus have also been reported [4]. Symptoms usually present in late adolescent unless the shunt is large with severe heart failure. The oldest age reported with this anomaly was 45 years [5].

Diagnosis is a real challenge for such anomaly. Echocardiography and contrast-enhanced CT are major investigations for conclusive diagnosis. In the presented case, we found unusual enlargement of the left atrium and mosaic flow from RPA-LA. Contrast-enhanced

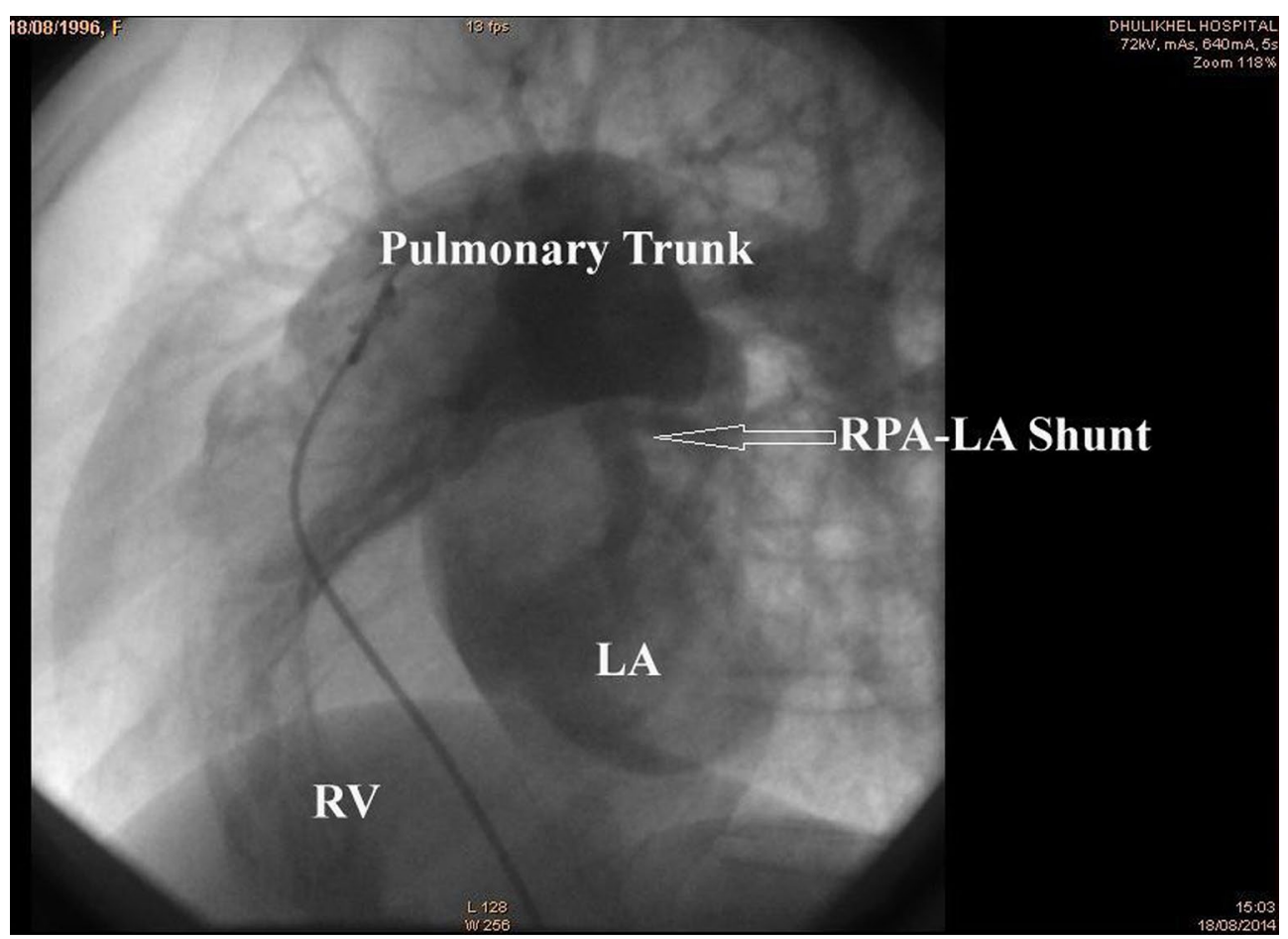

Fig. 5 Pulmonary arteriogram showing shunt 
CT chest was done which revealed the exact anatomical defect of a direct communication between the posterior part of the right pulmonary artery and the left atrium. There was an incidental association of angiolipoma in the right thoracic cage. Cardiac catheterization and selective angiography along with measurements of partial pressure of oxygen from the pulmonary artery, pulmonary veins and the left ventricle assisted in confirming the diagnosis.

Although transcatheter embolization would be accepted better treatment for patient with arteriovenous malformation, the significant number of complications outweigh the open heart surgery thus, a majority of PALAF cases have undergone surgical repair [6]. Elective surgery is the best treatment to prevent chronic arterial hypoxemia, systemic thromboembolism and pulmonary hypertension. Nevertheless, the surgical procedure has a considerable mortality risk $(22 \%)$ and should be approached with due caution.

\section{Conclusions}

In summary, the diagnosis of RPA-LA shunt is difficult and challenging. The unusual presentation of cyanotic congenital heart disease in late adolescent should also be considered a rare entity like RPA-LA shunt. Echocardiography, contrast-enhanced $\mathrm{CT}$ and selective angiographic studies are essential investigations for diagnosis and surgical closure of the shunt is the best available treatment modality.

\section{Consent}

Written informed consent was obtained from the patient for publication of this Case report and any accompanying images.

\section{Abbreviations}

BMI: body mass index; $\mathrm{CT}$ : computed tomography; $\mathrm{PaO}_{2}$ : partial pressure of oxygen; RPA-LA: right pulmonary artery to the left atrium.

\footnotetext{
Authors' contributions

TRS performed complete analysis, interpreted the findings and wrote the manuscript. HS performed echocardiograph, interpreted the report of CT findings and assisted arteriogram. JKS explained the CT findings correlating the clinical symptoms and confirming the diagnosis. KR performed the arteriogram further confirming the diagnosis. Similarly, KRM assisted in surgical procedure while correcting the shunt and explained the anomaly, which contributed designing the case. KCS prepared clinical history and physical examination including collection of all investigation reports and presented the case in academic discussion that made substantial contribution to prepare manuscript of the case. In addition, PN contributed in drafting and revising the manuscript critically. All authors read and approved the final manuscript.
}

\section{Author details}

1 Department of Cardiology, Dhulikhel Hospital, Kathmandu University Hospital, Dhulikhel, Nepal. ${ }^{2}$ Department of Radiology, Dhulikhel Hospital, Kathmandu University Hospital, Dhulikhel, Nepal. ${ }^{3}$ Department of Cardiovascular Surgery, Dhulikhel Hospital, Kathmandu University Hospital, Dhulikhel, Nepal. ${ }^{4}$ Department of Internal Medicine, Dhulikhel Hospital, Kathmandu University Hospital, Dhulikhel, Nepal. ${ }^{5}$ Department of Cardiology, Manipal College of Medical Sciences, Pokhara, Nepal.

\section{Acknowledgements}

It is my immense pleasure to submit the current manuscript in BMC Research Notes. I express sincere gratitude to Department of Cardiology, Kathmandu University Hospital and cardiac surgeons from national heart centre. Finally, I would like to thank Dhulikhel Hospital, Kathmandu University Hospital for all the financial support.

\section{Competing interests}

The authors declare that they have no competing interests. No funding was done.

Received: 28 November 2014 Accepted: 14 October 2015

Published online: 23 October 2015

\section{References}

1. Friedlich A, Bling RJ, Blount SG. Physiological studies in congenital heart disease. Circulatory dynamics in the anomalies of venous return to the heart including pulmonary arteriovenous fistula. Bull Johns Hopkins. 1950;86:20-57.

2. Margaryan R, Arcieri L, Cantinotti M, Murzi B. Surgical closure of a big pulmonary artery-left atrial fistula. Interact CardioVasc Thorac Surg. 2010;1:113-5

3. Lucas RV, Lund GW, Edward JE. Direct communication of the pulmonary artery with the left atrium. An unusual variant of pulmonary arteriovenous fistula. Circulartion. 1961;24:1409-14.

4. Kroeker EJ, Adams D, Leon AS, Pouget JM. Congenital communication between a pulmonary artery and the left atrium: physiologic observation and review of the literature. Am J Med. 1963;34:721-5.

5. Zeebregts CJ, Nijveld A, Lam J, Van Oort AM, Lacquet LK. Surgical treatment of a fistula between the right pulmonary artery and the left atrium: presentation of the two cases and review of literature. Eur J Cardiothorac Surg. 1997;11:1056-61.

6. Chowdhary UK, Airan B, Kothari SS, Pandey A, Subramanium KG, Venugopal P. Right pulmonary artery to left atrium communication. Ann Thorac Surg. 2005;80:365-70.

\section{Submit your next manuscript to BioMed Central and take full advantage of:}

- Convenient online submission

- Thorough peer review

- No space constraints or color figure charges

- Immediate publication on acceptance

- Inclusion in PubMed, CAS, Scopus and Google Scholar

- Research which is freely available for redistribution 